\title{
An Analysis of Virtual Flux Direct Power Control of Three- Phase AC-DC Converter
}

\author{
Nor Azizah Yusoff' ${ }^{1}$, Azziddin M. Razali², Kasrul Abdul Karim³, Auzani Jidin ${ }^{4}$, Tole Sutikno ${ }^{5}$ \\ 1,2,3,4 Faculty of Electrical Engineering, Universiti Teknikal Malaysia Melaka (UTeM), Malacca, Malaysia \\ ${ }^{5}$ Department of Electrical Engineering, Universitas Ahmad Dahlan, Yogyakarta, Indonesia
}

\begin{tabular}{l} 
Article Info \\
\hline Article history: \\
Received Mar 20, 2018 \\
Revised Mar 28, 2018 \\
Accepted Jul 1, 2018 \\
\hline
\end{tabular}

Keyword:

AC-DC Converter

Direct power ontrol

Dynamic condition

Steady State condition

Virtual-Flux Concept

\begin{abstract}
This paper presents an analysis of virtual-flux direct power control (VFDPC) technique for the three-phase pulse width modulation (PWM) ac-dc converter. The proposed VF-DPC is developed by assuming the grid voltage and converter line filters quantities are related to a virtual three-phase ac motor. The controller works with less number of sensors by eliminating the voltage sensors used for measuring the three-phase grid voltage. The grid virtual flux which is proportional to the grid voltage will be estimated from the information of converter switching states, line currents, and dc-link output voltage. Several analyses are performed in order to study the steady state and dynamic performance of the converter, particularly during the load and DC voltage output reference variations. The proportional integral (PI) controller gains at the outer voltage control loop of VF-DPC are tuned properly and the entire PWM ac-dc converter system is simulated using MATLAB/Simulink software to ensure the dc output voltage follows the desired output voltage under steady state and dynamic conditions. Ac-dc converter utilizing the proposed VF-DPC is able to generate three-phase input current waveforms that are almost sinusoidal with low harmonics contents which is less than $5 \%$ and near unity power factor $(p f)$ operation.
\end{abstract}

Copyright $@ 2018$ Institute of Advanced Engineering and Science. All rights reserved.

\section{Corresponding Author:}

Azziddin Bin Mohamad Razali

Faculty of Electrical Engineering,

Universiti Teknikal Malaysia Melaka (UTeM),

76100 Durian Tunggal, Malacca, Malaysia

Email: azziddin@utem.edu.my

\section{INTRODUCTION}

Research interest in the three-phase pulse width modulation (PWM) rectifiers or known as ac-dc converters in this paper has grown rapidly over the past few years due to numerous advantages such as bidirectional power flow capability, excellent control of dc-bus voltage, low total harmonic distortion of input currents and almost for unity power factor operation[1]. Performance of ac-dc converters is greatly dependent on the quality of the applied control techniques being used. The converters can be controlled by the control strategies analogous to the control methods of ac machines. The control schemes of grid connected ac-dc converter can be classified in two types, namely the voltage oriented control (VOC) which similar to the field-oriented control, and the direct power control (DPC) which imitates the basic idea of direct torque control of ac machines. The VOC guarantees high dynamic and static performance via internal current loop and is constantly being developed and improved by several researchers. On the other hand,-the successful operation of DPC is highly dependent on the effectiveness of the active and reactive power control loops performing their tasks [2-6].

However, the performance of conventional DPC strategy can be enhanced by introducing the new technique of power estimation which does not need the grid voltage information. The power estimation is performed by estimating the grid virtual flux [7][8]. Subsequently, the estimated grid virtual flux and the 
measured line currents information will be used to calculate the instantaneous active and reactive power. In reference [9], the used of the virtual flux (VF) signal for power estimation leads to the following advantages of the VF-DPC compared to the other conventional control methods of ac-dc converter such as the VF-DPC is able to operate under unbalanced and distorted supply voltage producing low total harmonic distortion of input current, unity power factor operation, excellent steady state and dynamic performances. Subsequently, by comparing the proposed VF-DPC with the conventional VOC, the VF-DPC requires simpler algorithm technique to estimate the input instantaneous active and reactive power, and perform other controller tasks due to the absence of current control loops, dq-coordinate transformation and separate PWM voltage modulator as required by the VOC.Indeed, there is no essential requirement for decoupling control of the active and reactive components.. Therefore, this paper is focussing on the performance studies related to the VF-DPC applied to the grid connected PWM ac-dc converter. The converter performance will be evaluated under steady state and dynamic conditions. The converter's dynamic study is performed by evaluating the transient response during the magnitude variations of DC voltage reference and load resistance.

\section{MODELLING OF THREE-PHASE AC-DC CONVERTER}

The structure of topology for three-phase bidirectional of an ac-dc voltage source converter is shown in Figure 1. The converter is connected to a three-phase ac supply and for each phase a series branch of inductor $L$ and internal resistance $R$ has been connected after the source in order to represents the internal impedance. Then, the six IGBTs which are parallel with free-wheeling diodes are involved in rectifying the input voltages. Nowadayas, the usage of power diode and thyristor rectifiers for ac to dc conversion is becoming a problem in transmission and distribution due to the harmonics and reactive currents they inject into the system. Perhaps, the non-sinusoidal shape of the input current drawn by the conventional ac-dc converter (rectifiers) generates significant harmonics components which will result in increasing the the voltampere rating of the utility equipment such as generators, transmission lines and transformers. Therefore, in this research insulated gate bipolar transistor (IGBT) is used as the converter bidirectional switches in the circuit via its simple and able to operate in high switching frequency [7]. Instead, this power switch can be the alternative to draw a continuous sinusoidal current from ac power supply with lower Total Harmonic Distortion (THD) and higher power factor (near unity). Finally, the capacitor is connected in parallel to smoothen the output of DC voltage.

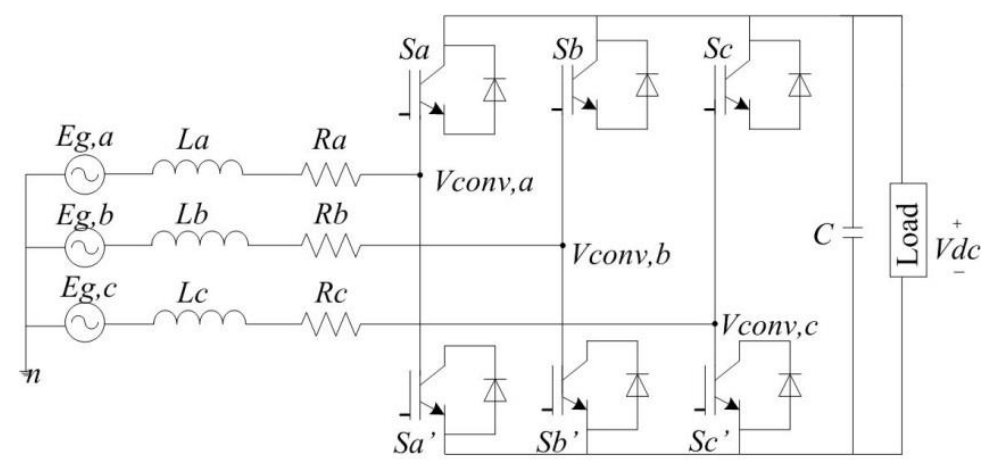

Figure 1. Three-phase PWM rectifier system for bidirectional power flow

\section{PRINCIPLE OPERATION OF VIRTUAL FLUX}

The Virtual Flux-Direct Power Control (VF-DPC) is used to estimates the input of instantaneous active and reactive powers as well as the three-phase grid voltage. The concept of VF-DPC is to combine the direct power control (DPC) scheme with the input voltage source estimation method in operating the threephase ac-dc converter [8]. An effective estimation of virtual flux procedure and selection of converter is determining the success of the combined operation. A simple low-pass filter is added into the system to compensate the errors in phase and magnitude produced during virtual flux estimation procedure. At the meantime, VF-DPC is corresponding to use in regulation of the line currents and the dc-link output voltage by control the input of instantaneous active and reactive power. The control structure of VF-DPC is shown in Figure 2. Based on figure, the utility grid source voltage is considered as a virtual ac machine. 


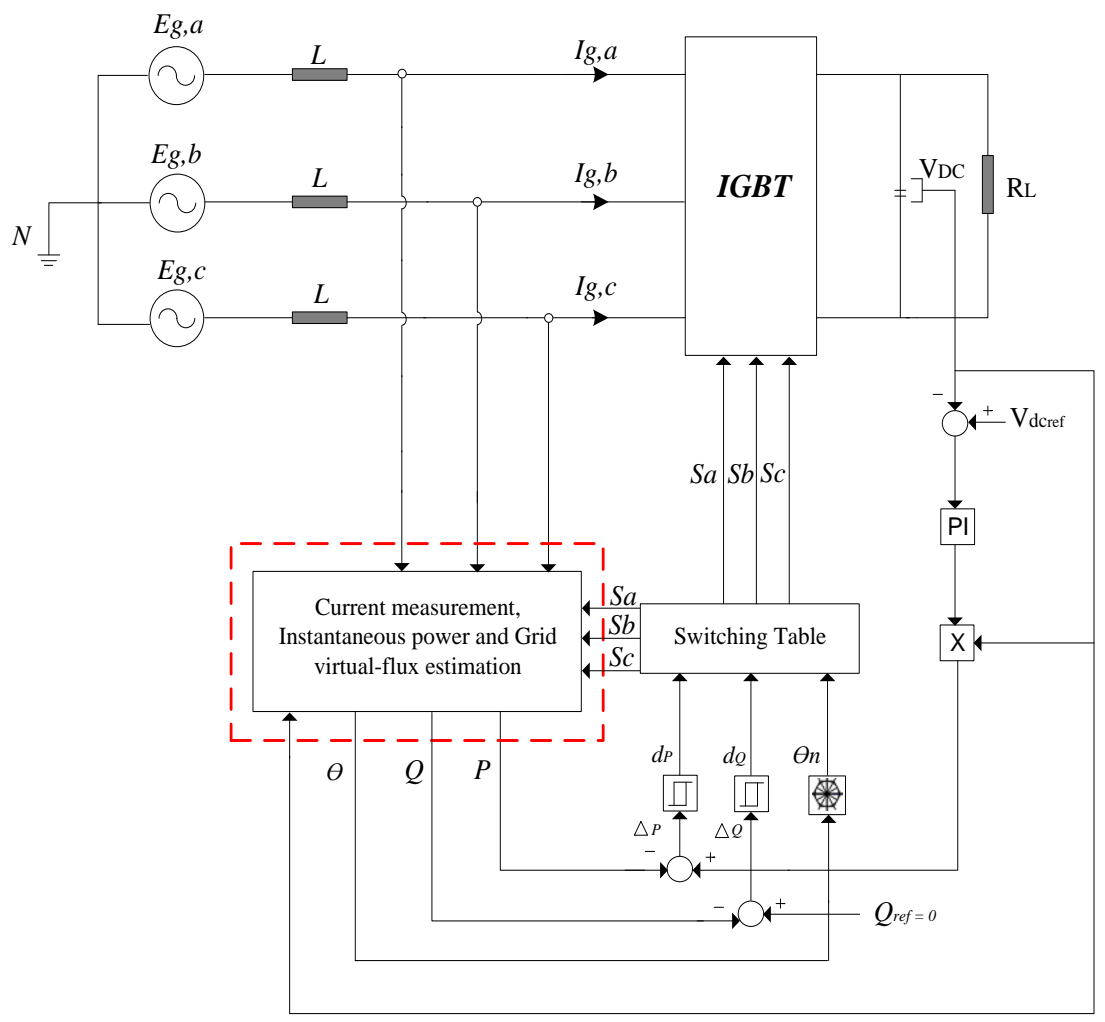

Figure 2. Control structure of virtual flux direct power control

By assuming a balanced three-phase system, the voltage and current equation of the pulse-width modulation (PWM)-controlled rectifier can be described by equation (1) from [5] where $E_{g, a b c}$ is the three-phase voltage supply, $I_{g, a b c}$ is the three-phase line current, and $V_{c o n v, a b c}$ is the three-phase converter pole voltage. Then, the phase voltages at the poles for each phase of the converter are equal as in equation (2) - (4) where $S_{a, b, c}$ the switching state of the converter is, and $V_{d c}$ is the link-output voltage.

$$
\begin{aligned}
& {\left[\begin{array}{l}
E_{g, a} \\
E_{g, b} \\
E_{g, c}
\end{array}\right]=R\left[\begin{array}{l}
I_{g, a} \\
I_{g, b} \\
I_{g, c}
\end{array}\right]+L \frac{d}{d t}\left[\begin{array}{l}
I_{g, a} \\
I_{g, b} \\
I_{g, c}
\end{array}\right]+\left[\begin{array}{l}
V_{c o n v, a} \\
V_{c o n v, b} \\
V_{c o n v, c}
\end{array}\right]} \\
& V_{c o n v, a n}=\left(2 S_{a}-\left(S_{b}+S_{c}\right)\right) \frac{V_{d c}}{3} \\
& V_{c o n v, b n}=\left(2 S_{b}-\left(S_{a}+S_{c}\right)\right) \frac{V_{d c}}{3} \\
& V_{c o n v, c n}=\left(2 S_{c}-\left(S_{a}+S_{b}\right)\right) \frac{V_{d c}}{3}
\end{aligned}
$$

Next, any three-phase electrical quantities in $a b c$-coordinates which are defined by $x_{\mathrm{a}, \mathrm{b}, \mathrm{c}}$ can further be transformed into stationary $\alpha \beta$-coordinates by using the the transformation matrix. 
$\left[\begin{array}{l}x_{\alpha} \\ x_{\beta}\end{array}\right]=\frac{2}{3}\left[\begin{array}{ccc}1 & -\frac{1}{2} & -\frac{1}{2} \\ 0 & \frac{\sqrt{3}}{2} & -\frac{\sqrt{3}}{2}\end{array}\right]\left[\begin{array}{l}x_{a} \\ x_{b} \\ x_{c}\end{array}\right]$

\section{VIRTUAL FLUX ESTIMATION}

The grid virtual flux vector in a stationary frame $\bar{\Psi}_{g, \alpha \beta}$ is defined as the integration of the grid voltage vector in a stationary reference frame $\bar{E}_{g, \alpha \beta}$ as shown below;

$$
\psi^{\prime} \operatorname{conv,\alpha \beta }=\int V_{\text {conv }, \alpha \beta}
$$

By applying the equation of virtual flux in (6), the grid virtual flux vector can be estimated as shown in

$$
\psi_{g, \alpha \beta}=\int\left(\bar{V}_{c o n v, \alpha \beta} d t+R I_{g, \alpha \beta}\right)+L I_{g, \alpha \beta}
$$

In practice, the value of internal line filter resistance $R$ can be neglected since its value is much smaller than the value of the line inductance impedance $Z_{L}$. Therefore, from equation (7) can be rewritten in the stationary coordinates for acquiring the magnitude of grid virtual flux at both real and complex axes as shown below

$$
\begin{gathered}
\psi_{g, \alpha}=\int V_{c o n v, \alpha} d t+L I_{g, \alpha} \\
\psi_{g, \beta}=\int V_{c o n v, \beta} d t+L I_{g, \beta}
\end{gathered}
$$

Then, the ideal integration that is used to calculate the grid virtual flux as shown in equation (8)-(9) might be saturated due to dc offset which is present in the sensed current or voltage. Thus, a low-pass filter is selected to replace the pure integrator. However, a simple low-pass filter reduces the system performance because it produces errors in the phase and magnitude of the virtual flux components calculations. In order to minimize these errors, equations in (8) and (9) are analyzed and adopted in the virtual flux estimation procedure which provides a low-pass filter characteristic at all frequencies. The $\alpha$ and $\beta$ components of the actual converter virtual flux $\Psi_{c o n v, \alpha \beta}$ are calculated based on the operating frequency with a given notation of $\omega_{e}$ or $\omega$, the low-pass filter cut-off frequency $\omega_{c}$, and the estimate of the converter pole flux vector $\Psi^{\prime}{ }_{c o n v, \alpha \beta}$. Those components can be written as. Therefore, Equation (10) and (11) are used in the virtual grid estimation procedure as illustrated in Figure 3.

$$
\begin{aligned}
& \psi_{\text {conv }, \alpha}=\psi^{\prime} \operatorname{conv}, \alpha^{\prime}+\psi^{\prime} \operatorname{conv}, \beta\left(\frac{\omega_{c}}{\omega_{e}}\right) \\
& \psi_{c o n v, \alpha}=\psi^{\prime} \operatorname{conv}, \alpha+\psi^{\prime} \operatorname{conv}, \beta\left(\frac{\omega_{c}}{\omega_{e}}\right)
\end{aligned}
$$




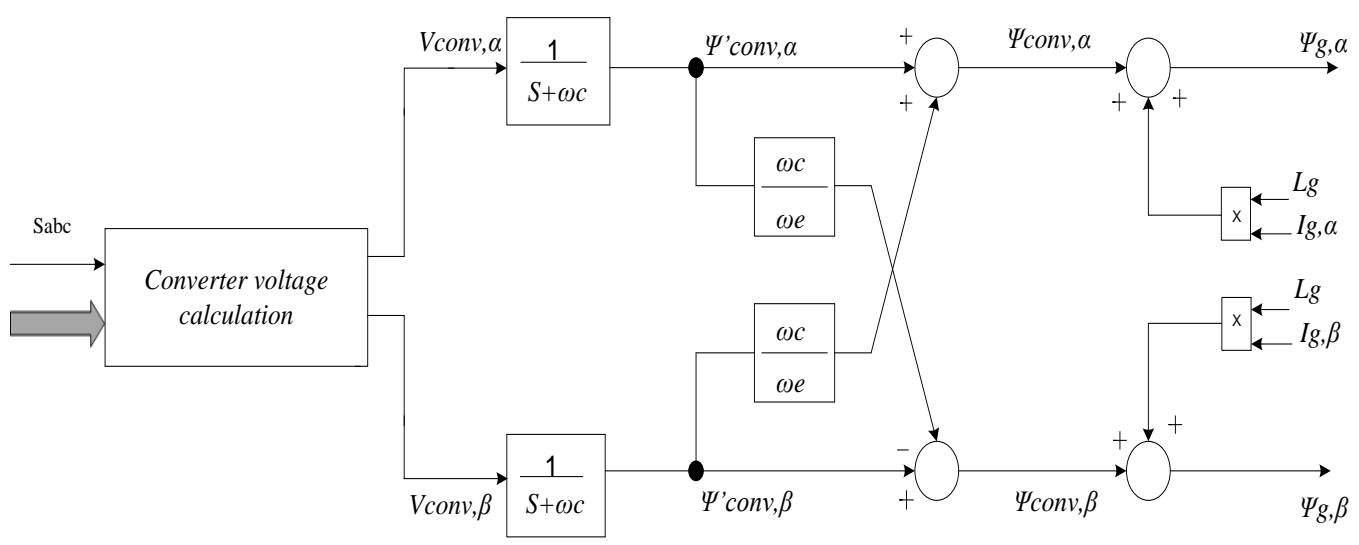

Figure 3. Control blocks for virtual flux estimation

Lastly, the estimation of the input active power $P$ and reactive power $Q$ in a stationary reference frame is given by (12) and (13), respectively

$$
\begin{gathered}
P=\left(\frac{3}{2}\right) \omega\left(\psi_{g, \alpha} I_{\beta}-\psi_{g, \beta} I_{\alpha}\right) \\
Q=\left(\frac{3}{2}\right) \omega\left(\psi_{g, \alpha} I_{\alpha}-\psi_{g, \beta} I_{\beta}\right)
\end{gathered}
$$

The input reactive power $\mathrm{Q}$ is set to zero to achieve a unity pf. In some applications, however, the front-end converter is required to operate in leading pf to compensate the motoring loads of lagging pf that are connected in a nearby utility grid. Figure 4 shows the sector selection for virtual flux vector. In VF-DPC, the switching look-up table works according to the virtual grid flux vector position which is rotating in a complex $\alpha \beta$-plane as shown in Figure 4. The virtual grid flux vector is divided into 12 sectors in the $\alpha \beta$-plane with each sector is $30^{\circ}$ wide. Due to the virtual flux vector is always lags $90^{\circ}$ behind its respective voltage vector, a sector which represents a voltage vector angle between $0^{\circ}$ to $30^{\circ}$ in a conventional DPC, is compatible to the virtual flux vector located in an angle between $-90^{\circ}$ and $-60^{\circ}$ as shown by sector 1 in Figure 4. The same technique is applied for the other 11 sectors. The main parameters used in the simulation are tabulated in Table 2.

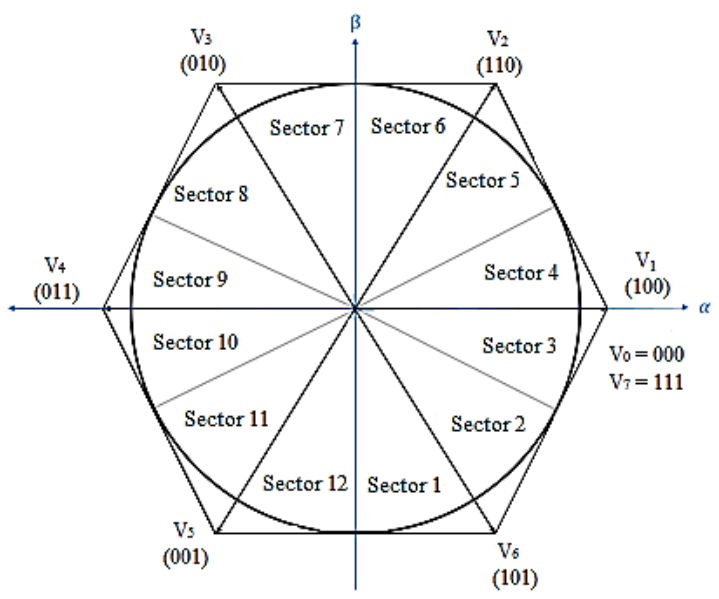

Figure 4. Sector selection for Virtual Flux Direct Power Control 
Table 1. Switching look-up table for virtual flux direct power control

\begin{tabular}{ccccccccccccccc}
\hline \begin{tabular}{c} 
Power error \\
\multicolumn{10}{c}{ Status }
\end{tabular} & \multicolumn{10}{c}{ Sector position $\left(\boldsymbol{\theta}_{\mathbf{n}}\right)$ and converter voltage vector $\left(\mathrm{V}_{\mathbf{n}}\right)$} \\
\hline $\boldsymbol{d} \boldsymbol{\boldsymbol { P }}$ & $d_{Q}$ & $\theta_{1}$ & $\theta_{2}$ & $\theta_{3}$ & $\theta_{4}$ & $\theta_{5}$ & $\theta_{6}$ & $\theta_{7}$ & $\theta_{8}$ & $\theta_{9}$ & $\theta_{10}$ & $\theta_{11}$ & $\theta_{12}$ \\
$\mathbf{0}$ & 0 & $\mathrm{~V}_{1}$ & $\mathrm{~V}_{1}$ & $\mathrm{~V}_{2}$ & $\mathrm{~V}_{2}$ & $\mathrm{~V}_{3}$ & $\mathrm{~V}_{3}$ & $\mathrm{~V}_{4}$ & $\mathrm{~V}_{4}$ & $\mathrm{~V}_{5}$ & $\mathrm{~V}_{5}$ & $\mathrm{~V}_{6}$ & $\mathrm{~V}_{6}$ \\
$\mathbf{0}$ & 1 & $\mathrm{~V}_{2}$ & $\mathrm{~V}_{2}$ & $\mathrm{~V}_{3}$ & $\mathrm{~V}_{3}$ & $\mathrm{~V}_{4}$ & $\mathrm{~V}_{4}$ & $\mathrm{~V}_{5}$ & $\mathrm{~V}_{5}$ & $\mathrm{~V}_{6}$ & $\mathrm{~V}_{6}$ & $\mathrm{~V}_{1}$ & $\mathrm{~V}_{1}$ \\
$\mathbf{1}$ & 0 & $\mathrm{~V}_{6}$ & $\mathrm{~V}_{6}$ & $\mathrm{~V}_{1}$ & $\mathrm{~V}_{1}$ & $\mathrm{~V}_{2}$ & $\mathrm{~V}_{2}$ & $\mathrm{~V}_{3}$ & $\mathrm{~V}_{3}$ & $\mathrm{~V}_{4}$ & $\mathrm{~V}_{4}$ & $\mathrm{~V}_{5}$ & $\mathrm{~V}_{5}$ \\
$\mathbf{1}$ & 1 & $\mathrm{~V}_{3}$ & $\mathrm{~V}_{3}$ & $\mathrm{~V}_{4}$ & $\mathrm{~V}_{4}$ & $\mathrm{~V}_{5}$ & $\mathrm{~V}_{5}$ & $\mathrm{~V}_{6}$ & $\mathrm{~V}_{6}$ & $\mathrm{~V}_{1}$ & $\mathrm{~V}_{1}$ & $\mathrm{~V}_{2}$ & $\mathrm{~V}_{2}$ \\
\hline
\end{tabular}

Table 2. Electrical Parameters of Power Circuit

\begin{tabular}{lc}
\hline \multicolumn{1}{c}{ Parameters } & Value \\
\hline Input phase voltage (peak), $\mathbf{E}_{\mathbf{g}}$ & $70.71 \mathrm{~V}$ \\
Source Voltage frequency, $\mathbf{f}$ & $50 \mathrm{~Hz}$ \\
Dc-link volatage reference, $\mathbf{V}_{\mathbf{d c}, \text { ref }}$ & $150 \mathrm{~V}$ \\
Resistance of reactance, $\mathbf{R}$ & $0.2 \Omega$ \\
Inductance of reactance, $\mathbf{L}$ & $18 \mathrm{mH}$ \\
Dc-link capacitor, $\mathbf{C}$ & $10.8 \mathrm{mF}$ \\
Load Resistance, $\mathbf{R}_{\mathbf{L}}$ & $140 \Omega$ \\
Sampling time, $\mathbf{t}_{\mathrm{s}}$ & $20 \mu \mathrm{s}$ \\
\hline
\end{tabular}

The, dc-bus voltage is regulated by controlling the active power. This can be achieved by using a PI controller. A simple PI controller is constructed as shown in Figure 5. The PI controller is fed by the DC-link and reference voltage. The output from the PI controller is the reference active power, $P_{\text {ref }}$ which will be compared with the actual instantaneous active power, $P$ to obtain the active power error, $P_{\text {err }}$. The power error is one of the parameters which will determine the switching state of the converter. Values of the proportional gain, $K_{p}$ and the integral gain, $K_{i}$ are chosen based on trial and error method. In this study, $K_{p}$ and $K_{i}$ are set to 5 and 25 , respectively.

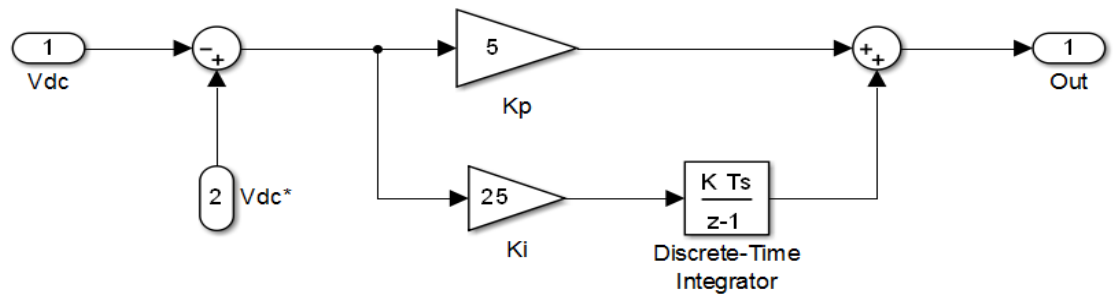

Figure 5. Subsystem for PI controller

\section{RESULT AND DISCUSSION}

The entire ac-dc converter system is simulated in the Matlab/Simulink environment in order to study its performance under steady-state and dynamic conditions. The output dc voltage obtained after the implementation of VF-DPC method is shown in Figure 6. It can be seen that there is an increment in rising time and settling time before the output voltage reaches the steady state. This is due to the tuning of PI controller which involves increasing value of $\mathrm{K}_{\mathrm{p}}$ and $\mathrm{K}_{\mathrm{i}}$.

Then, in Figure 7 is represent the simulated of basic signal from input voltage and current waveforms phase " $a$ " in phase. Basically, it can be seen that the concept of virtual flux is able to produce line voltage and currents at a unity power factor $(p f)$. Additionally, this control system of virtual flux is also capable to produce a current waveform which is almost sinusoidal compare by the signal from the conventional control method of direct power control (DPC). Therefore Figure 8 has represents balanced three-phase line current waveforms during steady-state condition by VF-DPC. 


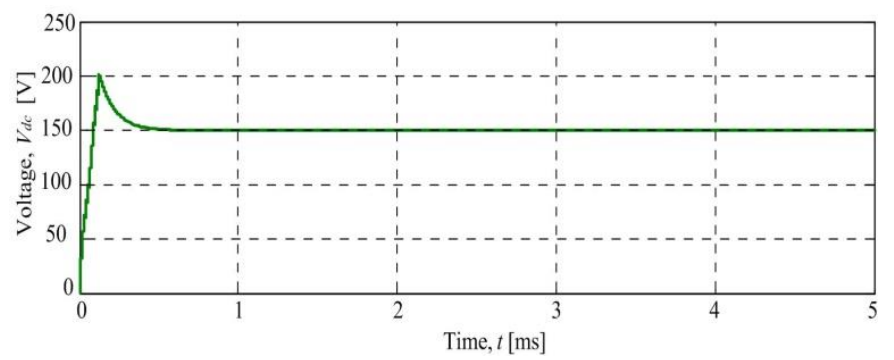

Figure 6. Output voltage, $\mathrm{V}_{\mathrm{O}}$ after implementation of VFDPC

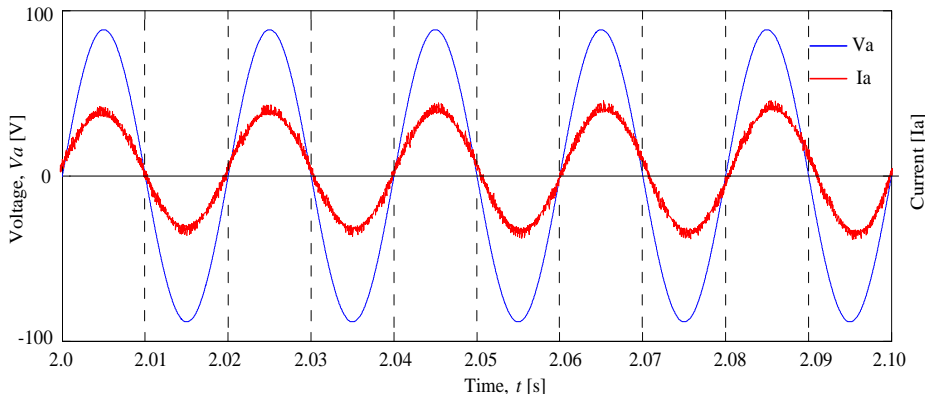

Figure 7. Phase a voltage and current at unity power factor, $p f$

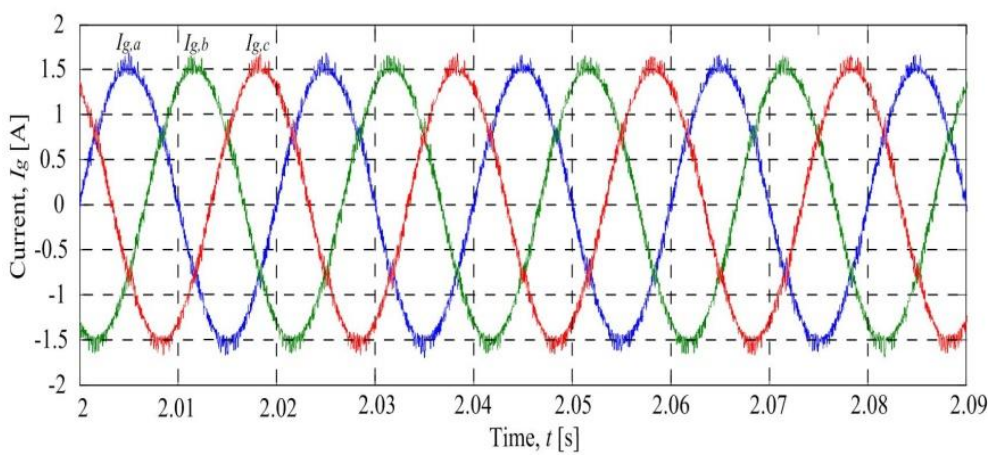

Figure 8 . Three phase input current by VF-DPC

In fact, the current waveform which is almost to be more sinusoidal will have a lower frequency component in it thus contributing to the lowest value of harmonic distortion for the signal. Therefore, the comparison of the total harmonic distortion (THD) of the input line current from both control method VFDPC and conventional of DPC is shown in Figure 9. It is apparent to see from the simulation result, the harmonic rate of virtual flux is $4.19 \%$ compare to the THD from conventional of DPC which is $4.88 \%$ higher than VF-DPC control method even both of this control method complies with IEEE-519 standard requirement of less than $5 \%$. The frequency spectrum of the line current reveals that, due to the hysteresis controller operation, the VF-DPC generates variable switching frequency with the harmonic components spread over a wide range frequency. 

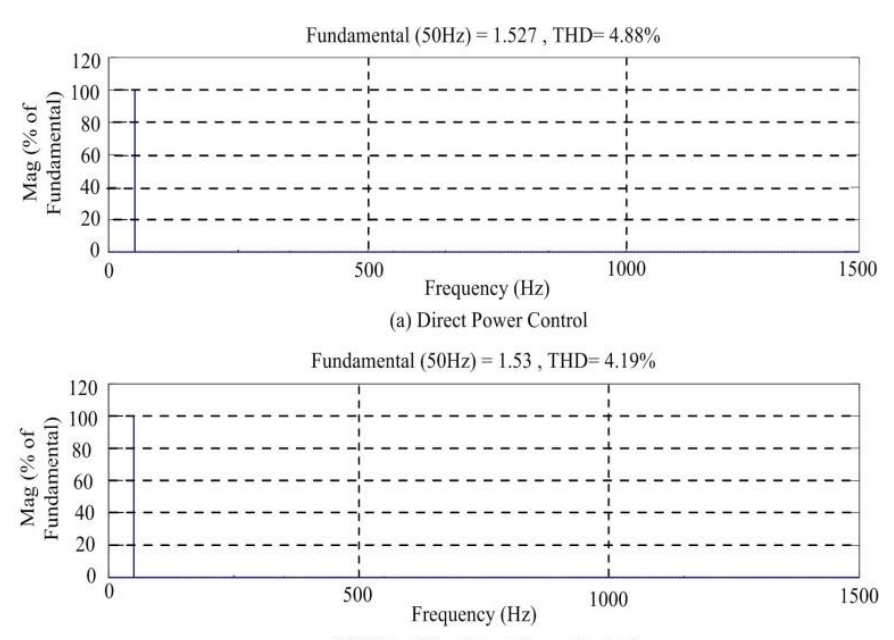

(b) Virtual Flux Direct Power Control

Figure 9. Harmonic spectrum of the line current generated by VFDPC

Hence, Figure 10(a) has shown the transient response when the dc voltage reference changes from 150 to $180 \mathrm{~V}$ at $5 \mathrm{~s}$ and back to $150 \mathrm{~V}$ at $8 \mathrm{~s}$ while Figure 10 (b) shown when it change from 150 to $120 \mathrm{~V}$ at 5 $\mathrm{s}$ and back to $150 \mathrm{~V}$ at $8 \mathrm{~s}$. With the estimated quantities of the dc link voltage proportional-integral (PI) regulator, the control performance is satisfactory even though there are overshoot and undershoot in both responses before reaching steady state when voltage changes. The controller enables the output voltages to reach the desired reference voltage $(150 \mathrm{~V})$.

Next, the control method is also evaluated under the transient response during load variation. In this variation, $100 \Omega$ resistors are connected in parallel towards the existing resistor across the DC link at $3 \mathrm{~s}$ to create a sudden disturbance to the load current which is performed by adding a breaker. In Figure 11(a)-(c) has shown the result for transient responses during a load variation. It is apparent to see that at the time of $3 \mathrm{~s}$ the line current waveform from phase ' $a$ ' started to increases once the disturbance occurs at time of $3 \mathrm{~s}$ regarding to the relationship of current and resistance in ohm's law. Then, dc output voltage are sudden drop or experiencing a small dip but it recovers to the original value $150 \mathrm{~V}$ because the forced of voltage PI regulator. Lastly in Figure 12(c) the estimated active power $(\mathrm{P})$ follows the change in load as it increases suddenly at $3 \mathrm{~s}$ due to the load disturbance. Meanwhile, the overshoot and oscillation are not obvious for reactive power $(\mathrm{Q})$.

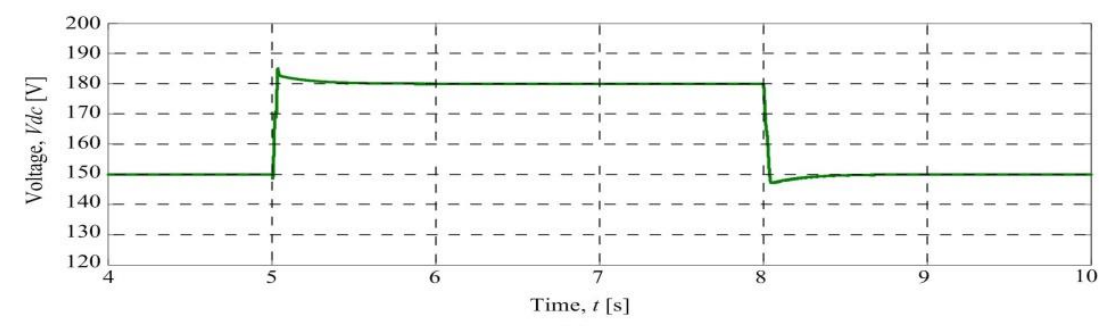

(a)

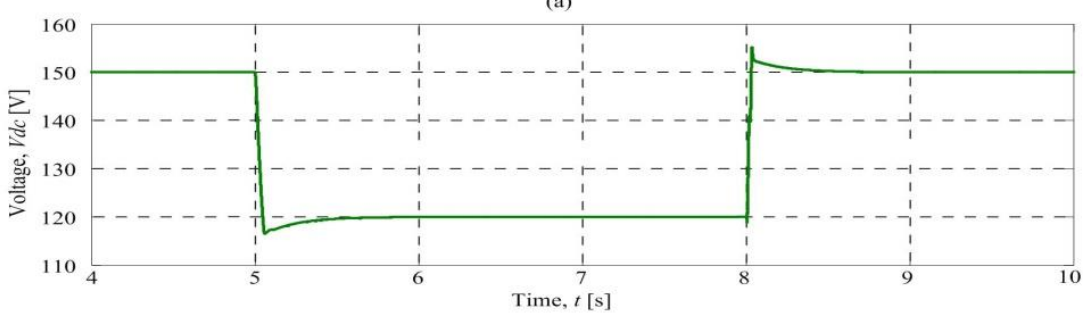

(b)

Figure 10. Transient response for the step changes of the dc-link voltage 


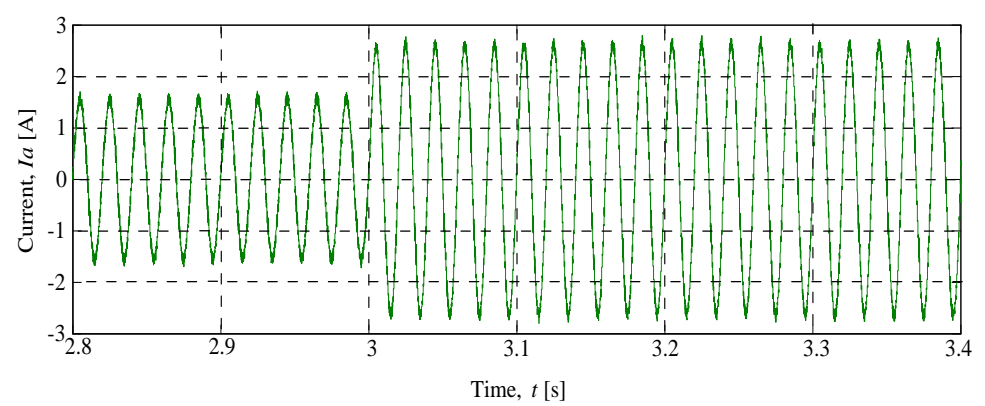

(a)

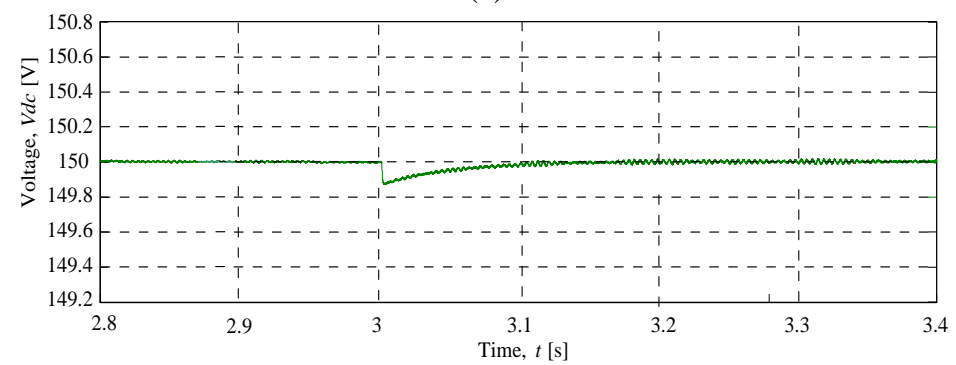

(b)

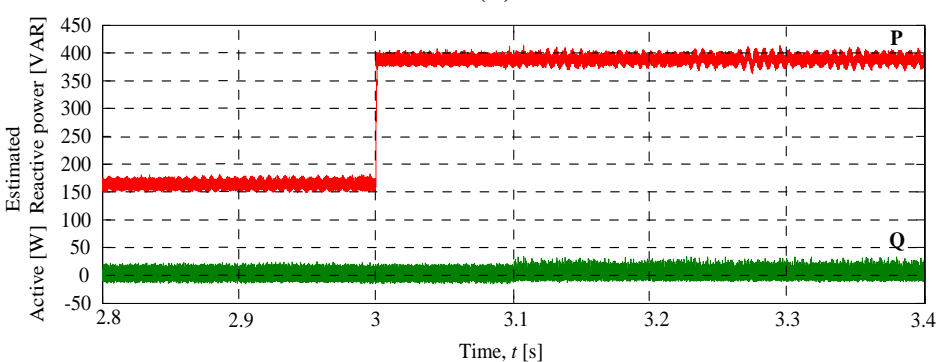

(c)

Figure 11. (a) Transient response for load variation from low to high current demand for phase $a$ current (b) DC-link voltage (c) Estimated active and reactive powers

\section{CONCLUSION}

The presented Direct Power Control (DPC) system constitutes a viable alternative to the pulse width modulated three-phase ac-dc voltage source converter. In the DPC the active and reactive powers are used as the controlled output. The appropriate selecting for the switching states from a switching table is based on the errors between estimation and the desired active and reactive powers. Conversely, a new control scheme as an extension from the DPC which is based on the estimation of grid voltage and the instantaneous of active and reactive power calculation known as Virtual Flux Direct Power Control (VF-DPC) is analyze in this work and are successfully simulated in the Matlab/Simulink block diagram. Basically, the VF-DPC is capable to minimizing the employment of sensors by eliminating the used of three voltage sensors which is located at the input side of the ac-dc converter. Those three voltage sensors are essential in a conventional DPC in order to measure the three phase supply voltage. Hence, the size and cost of the ac-dc converter system can be reduced. Otherwise, from the simulation result indicate that the performance of a VF-DPC is better than the conventional of DPC regarding to the lower value of total harmonic distortion (THD). Therefore, the presented VF-DPC is capable to generating smooth input currents waveforms. Then, in study for the dynamic performance for the variation in load and DC voltage reference, it is observed that the output voltage recovers close to the reference voltage despite the sudden disturbance introduced to the system. The proper tuning of PI controller enables the output voltage remains near to reference voltage. Meanwhile, the active power increases significantly when a smaller resistance value is connected parallel with existing circuit which reduces the overall load. 


\section{ACKNOWLEDGMENT}

The authors would like to thank toward 'Skim Zamalah' from Universiti Teknikal Malaysia Melaka (UTeM)' as providing for continuous financial support that enabled the achievement of this research result and Ministry of Education (KPM) for sponsoring this research work under grant (FRGS/1/2016/TK04/UTEM/02/11/F00307).

\section{REFERENCES}

[1] M. Malinowski, M. P. Kazmierkowski, and A. M. Trzynadlowski, "A Comparative Study of Control Techniques for PWM Rectifiers in AC Adjustable Speed Drives," in IEEE Transaction Power Electronics, vol. 18, no. 6, pp. 1390-1396, 2003.

[2] T. Geyer, "A Comparison of control and modulation schemes for medium-volatge drives: Emerging predictive control concepts versus Field Oriented Control” IEEE Energy Conversion Congress and Exposition, pp. 2836-2843, 2010

[3] Handy Mohamed Soliman, "Perfomance Characteristic of Induction Motor with Field Oriented control Compared to Direct Torque Control" International Journal of Power Electronics and Drive System (IJPEDS), vol.7, no.4, pp.1125-1133, December 2016

[4] G. P. Kondylis, G. A. Vokas, A. G. Anastasiadis and S. A. Konstantinopoulos, "Application of voltage oriented control techniques in a fully renewable, wind powered, autonomous system with storage capabilities" AIP Conference Proceeding 1814, vol. 1814, issue 1, 2017

[5] Nor Azizah Yusoff, Azziddin M. Razali, Kasrul Abdul Karim, Auzani Jidin, Tole Sutikno, "A Concept of Virtual flux Direct Power Control of Three-phase AC-DC Converter, "International Journal of Power Electronics and Drive Systems (IJPEDS), Vol. 8, No. 4, pp. 1776-1784, December 2017,

[6] A. M. Razali, M.A. Rahman, Glyn George, "An Analysis of Direct Power control for Three Phase AC-DC Converter," in Industry Applications Society Annual Meeting (IAS), pp. 1-7, 2012 IEEE

[7] A. M. Razali, M.A. Rahman, Glyn George and N. A. Rahim "Analysis and Design of New Switching Lookup Table for Virtual Flux Direct Power Control of Grid-Connected Three-Phase PWM AC-DC Converter," in IEEE Transaction on Industry Application, vol. 51, no. 2, pp. 1189-1199, 2015

[8] Bouzidi Mansour, Bouafia Saber, Bouzidi Ali, Benaissa Abdelkader, Barkat Said, "Application of Backstepping to the Virtual Flux Direct Power Control of Five-Phase Shunt Active Power Filter" International Journal of Power Electronics and Drive System (IJPEDS), vol.4, no.2, pp.173-191, June 2014

[9] M. Malinowski, M. P. Kazmierkowski, S. Hansen, F. Blaabjerg and G. D. Marques "Virtual-Flux-Based Direct Power Control of Three-Phase PWM Rectifiers," in IEEE Transaction on Industry Applications, vol. 37, no. 4, pp. 1019-1027, 2001

[10] A. M. Razali, M.A. Rahman, "Performance Analysis of Three-Phase PWM Rectifier Using Direct Power Control," in International Electric Machines \& Drives Conference(IEMDC), pp. 1603-1608, 2011 IEEE

[11] A. M. Razali, M.A. Rahman, "Virtual Grid Flux Oriented Control Method for Front-End Three Phase Boost Type Voltage Source Rectifier," in IEEE Canadian Conference on Electrical and Computer Engineering(CCECE), 2012

[12] F. Busschots, R. Belmans and W. Geysen, "Application of Field Oriented Control in Crane Drives" Industry Applications Society annual meeting, pp. 347-353, 1991

[13] Y. Zhang, Y. Peng, and C. Qu, "Comparative Study of Model Predictive Control and Direct Power Control for PWM Rectifiers With Active Power Ripple Minimization" in Energy Conversion Congress and Exposition (ECCE), 2015 IEEE, pp. 3823-3830, 2015.

[14] G. Escobar, A. M. Stankovic, J. M. Carrasco, E. Galvan and R. Ortega, "Analysis and Design of Direct Power Control (DPC) for A Three Phase Synchronous Rectifier Via Output Regulation Subspaces," in Power Electronics, IEEE Transaction on, vol. 18, pp. 823-830, 2003

[15] B. Singh, B. N. Singh, A. Chandra, K. Al-Haddad, A. Pandey and D. P. Kothari "A Review of Three-Phase Improved Power Quality AC-DC Converters," in IEEE Transaction on Industry Electronics, vol. 51, no. 3, pp. 641659,2004

[16] T. Noguchi, H. Tomiki, S. Kondo, and I. Takahashi "Direct Power Control of PWM Converter without PowerSource Voltage Sensor,” in Industry Application, IEEE Transaction on, vol. 34, pp. 473-479, 1998.

[17] J. Eloy-Garcia and R. Alves, "DSP-based Direct Power Control of a VSC with Voltage Angle Estimation," in Transmission \& Distribution Conference and Exposition : Latin Amerika, TDC IEEE/PES, pp. 1-5, Jul. 2006.

[18] M. Cirrincione, "Direct Power Control of Three Phase VSIs for the Minimization of Common-Mode Emmission in Distributed Generated System," Electric Power Sysem. Research., vol. 81, pp. 830-839, May 2011.

[19] R. Wu, S.B. Dewan and G. R. Slemon "Analysis of an AC to DC Voltage Source Converter using PWM with Phase and Amplitude Control," in Industry Application Society Annual Meeting, 1989, Conference Record of the 1989 IEEE, vol. 1, pp. 1156-1163, 1989.

[20] B. T. Ooi, J. C. Salmon, J. W. Dixon, and A. B. Kulkarni "A Three Phase Controlled-Current PWM Converter with Leading Power Factor,” Industry Application, IEEE Transaction on, vol. IA-23, pp. 78-84, 1987.

[21] L. A. Serpa, S. Ponnaluri, P. M. Barbosa, and J. W. Kolar, "A Modified Direct Power Control Strategy Allowing the Connection of Three-Phase Inverters to the Grid Through LCL Filters," in Industry Applications, IEEE Transaction on, vol. 43, pp. 1388-1400, 2007. 